\title{
Gadobenate Dimeglumine
}

National Cancer Institute

\section{Source}

National Cancer Institute. Gadobenate Dimeglumine. NCI Thesaurus. Code C77547.

A gadolinium-based paramagnetic contrast agent. When placed in a magnetic field, gadobenate dimeglumine produces a large magnetic moment and so a large local magnetic field, which can enhance the relaxation rate of nearby protons; as a result, the signal intensity of tissue images observed with magnetic resonance imaging (MRI) may be enhanced. Because this agent is preferentially taken up by normal functioning hepatocytes, normal hepatic tissue is enhanced with MRI while tumor tissue is unenhanced. In addition, because gadobenate dimeg lumine is excreted in the bile, it may be used to visualize the biliary system using MRI. 